\title{
Experimental and Analytical Investigation Based on 1/2 Scale Model for a Cleanroom Unit Module Consisting of Steel Section and Reinforced Concrete
}

\author{
Sijun Kim ${ }^{1}$ and Se Woon Choi ${ }^{2}$ \\ ${ }^{1}$ Department of Plant Architectural Engineering, Kyonggi University, Suwon, Kyonggido 16227, Republic of Korea \\ ${ }^{2}$ Department of Architecture, Catholic University of Daegu, Kyeongsan-si, Kyeongbuk 38430, Republic of Korea
}

Correspondence should be addressed to Se Woon Choi; watercloud@cu.ac.kr

Received 20 May 2016; Revised 21 June 2016; Accepted 23 June 2016

Academic Editor: Gilson R. Lomboy

Copyright (C) 2016 S. Kim and S. W. Choi. This is an open access article distributed under the Creative Commons Attribution License, which permits unrestricted use, distribution, and reproduction in any medium, provided the original work is properly cited.

\begin{abstract}
The rapid advances in high tech industries and the increased demand for high precision and reliability of their production environments call for larger structures and higher vertical vibration performance for high technology facilities. Therefore, there is an urgent demand for structural design and vertical vibration evaluation technologies for high tech facility structures. For estimating the microvibration performance for a cleanroom unit module in high technology facilities, this study performs the scale modeling experiment and analytical validation. First, the $1 / 2$ scale model (width $7500 \mathrm{~mm}$, depth $7500 \mathrm{~mm}$, and height $7250 \mathrm{~mm}$ ) for a cleanroom unit module is manufactured based on a mass-based similitude law which does not require additional mass. The dynamic test using an impact hammer is conducted to obtain the transfer function of $1 / 2$ scale model. The transfer function derived from the test is compared with the analytical results to calibrate the analytical model. It is found that, unlike for static analyses, the stiffness of embedded reinforcement must be considered for estimating microvibration responses. Finally, the similitude law used in this study is validated by comparing the full-scale analytical model and 1/2 scale analytical model for a cleanroom unit module.
\end{abstract}

\section{Introduction}

Advances in information communication technology and production technology in recent years have increasingly sophisticated high technology products, such as semiconductors, liquid crystal displays (LCD), and optical microscopes. Demands for these products are predicted to rise further as they make our lives more convenient.

Semiconductors, LCD, and optical microscopes require high precision, and thus their production equipment and facilities must satisfy stringent terms. Vertical vibration that occurred must be strictly controlled because vertical vibration exposure during production increases production error and results in defects. Therefore, manufacturers of the production equipment conduct vibration tests and disclose vibration specifications for their equipment [1].

Vibration performances provided by manufacturers are based on vibration testing in an environment controlled for vibration, temperature, and humidity. Therefore, to exhibit the vibration performance of a piece of equipment, an environment with extremely limited vibrations is required. However, it is difficult to satisfy such stringent conditions in regular production environments. A variety of vibration sources (e.g., traffic, personnel activities, and motion of motor in equipment) are present in high technology facilities that produce vibration-sensitive products, and resulting vibrations are transferred to the high technology equipment via the structures consisting of the facility (e.g., columns, beams, and floor plates), ultimately undermining the precision of the production process. Hence, strict management of vibration performance of structures consisting of high technology facilities as well as high technology equipment is demanded.

The vibration performance of structures is evaluated using generic vibration design criteria, rather than specific criteria for each piece of equipment [2-6]. The criteria take the form of a set of one-third-octave band velocity spectra labeled vibration criterion curves VC-A through 
VC-E and are known as the BBN Criterion Curves [4]. These curves have been used for evaluations of microvibration performance of various structures within high technology facilities [7-10].

For general structures, the structural design strategy that the structures are more flexible so as to buffer the shocks of lateral loads such as earthquakes is employed [11-13]. This is because a flexible structure has a lower risk for resonance, which would reduce vibration resonance. However, this is not the solution for microvibration of high technology facility structures. These structures cannot be simply designed to be flexible because the types and frequencies of vibrations that affect the floor-upon which high technology equipment is installed-are diverse. Furthermore, while specific vibration frequencies or regions are dominant in general buildings, those are not dominant in the floor structural systems. For these reasons, it is difficult to avoid the resonance frequency through designing floor structures flexibly.

Thus, the problems of microvibration in the high technology facility structures are addressed by maximizing the stiffness of the structures to prevent resonance below a certain vibration frequency [14]. It is necessary that stiffness of the structures be increased because the high accuracy equipment generally is more sensitive to low frequencies. The primary natural frequency of vertical vibrations in the floor structures of general office buildings ranges from 5 to $10 \mathrm{~Hz}$ while that of structures within high technology facilities ranges from 10 to $20 \mathrm{~Hz}$.

Microvibration performance in the high technology facility structure is affected by the size and arrangement of structural members, story height, and span length, so these should be taken into consideration during the design process [14-17]. Despite such significance, research literatures on the structural design and microvibration performance evaluation of the high technology facility structure have been relatively limited. One reason is that design data for high technology facility are generally not open to the public.

Furthermore, experimental data and structural analysis modeling techniques are required to develop structure design and performance evaluation technologies. However, high technology facility structures are bound to be largescale in terms of story height, span length, and crosssectional size of members compared to those of general buildings because of production and environmental equipment as well as vibration performance requirements. The problems of costs and space induced by such large sizes have crippled research efforts on experimental evaluations and structural analysis modeling of high technology facility structures. However, the rapid advances in high tech industries and the increased demand for high precision and reliability of their production environments call for larger structures and higher vibration performance for high technology facilities. Therefore, there is an urgent demand for structural design and vibration evaluation technologies for high tech facility structures, which in turn call for more vigorous experimental and analytical studies on this matter.

Studies in various aspects of high tech facility structures are required. But most of all, we must verify the vibration performances of these facilities as designed with conventional techniques. Performance evaluations for vibration should be conducted at the building level because a variety of building members and conditions affect vibration performance. By and large, a vibration analysis is performed to evaluate vibration response to be reflected on the design of high tech plants that require stringent management of microvibration. However, the theoretical and practical limitations of structural analysis technology generate a gap between the actual vibration and the computed vibration of the structure. Therefore, more experimental studies are required to develop and improve structural design techniques for high tech facility structures.

Experimenting with the full-scale structures would produce the most accurate results with regard to the vibration properties of a specific structure, but such experiments are practically impossible due to spatial limitations as well as cost and time inefficiency. Therefore, scale models are usually manufactured for experiments. Existing studies using scale models mostly focused on the evaluation of seismic performance or wind performance of structures [18-23], and experimental studies to evaluate the microvibration performance of high tech facility structures have rarely been reported.

This study seeks to conduct an experiment to analyze the differences in the actual and analytical measurements so as to develop data for future references for designing microvibration control in high tech facility structures. To this end, we manufactured the $1 / 2$ scale model according to the mass-based scaling method. It is quite difficult to predict the performance of the actual structure by experimenting with a scale model. Hence, the existing scale model studies employ the similitude law, which defines the scale effects in physical terms. However, scaling down a structure is associated with a variety of variables, and some factors cannot be quantitatively scaled down. In other words, it is impossible to apply an identical similitude for all variables. Hence, an appropriate scaling method should be selected to meet specific experimental objectives and conditions. This study selects the mass-based scaling method for microvibration evaluation of high tech facility structures by analyzing the general scaling methods (i.e., mass-based, time-based, and acceleration-based). The mass-based scaling method does not require additional masses. The others require additional masses where it is difficult to conduct the scale model experiment of high tech facility structures.

The dynamic experimental test using an impact hammer is performed on the scaled-down model, and the transfer function is found based on this data. Transfer functions include the dynamic characteristic information for higherorder modes (e.g., 1st, 2nd, and 3rd) and thus are the most popular index in identifying structural properties [24]. In the present study, the transfer function acquired from the experiment is used as a comparative index to validate the analytical modeling technique. It is known that nonstructural components such as partition walls, infilled walls, external walls, and elevator shafts as well as the structural components affect the stiffness and frequencies of buildings $[25,26]$. These effects should be considered to obtain the simulation model 


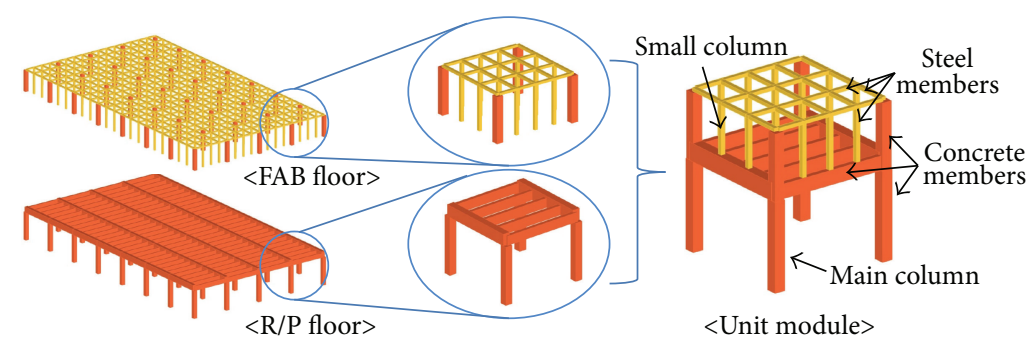

Figure 1: The example of the unit module consisting of high tech facility structures.

that shows the good agreement with the behaviors of real structures.

A small-scale model must be able to generate results that reliably mock the prototype's behaviors. To validate these results, a full-scale model in addition to the small-scale model must be manufactured to compare and analyze the results with identical experimental methods. In particular, because the scale model used in this study is a complex structure comprising steel members and reinforced concrete (RC) members, the similitude of the scale model must be validated. However, manufacturing a full-scale model of high tech facility structures is realistically impossible as their long span lengths and high story heights require considerable costs, large spaces, and risky experiments. Therefore, we additionally perform an analytical modeling for the prototype using an analytical modeling technique verified via the $1 / 2$ scale model experiment. To validate the similitude law used in this study, the analytic results obtained from both the scale model and prototype are compared.

\section{Cleanroom in High Tech Facility Structures}

Industrial facilities that produce high-precision products, such as semiconductors, LCD, and optical microscopes, are equipped with a space called a cleanroom [27-29]. A cleanroom is an environmentally controlled space in which contaminants such as airborne dusts or hazardous gases are regulated to meet stringent standards.

Cleanrooms require air conditioning equipment to maintain a clean air environment. Airflow within a cleanroom can be divided into vertical laminar airflow, horizontal laminar airflow, and turbulent airflow. Despite high initial costs and maintenance fees, vertical laminar airflow is the mostly widely used type because it can maintain a highly clean environment with minimal influence from personnel.

As shown in Figure 1, vertical laminar airflow is arranged such that a unit module comprising a fabrication (FAB) level and return plenum $(\mathrm{R} / \mathrm{P})$ level is continuously repeated. Production equipment is installed on the FAB level and the $\mathrm{R} / \mathrm{P}$ level refers to the space in the lower section of FAB level to circulate air injected from the ceiling of the FAB level. Supply/exhaust duct, cable, and pipe are installed on the R/P level. The FAB level must meet stringent vibration specifications as high technology production activities are performed at this level. Therefore, the FAB level must be highly stiff, which is achieved by densely positioning small columns between the FAB and $\mathrm{R} / \mathrm{P}$ levels. The main columns that support the
FAB level are relatively widely spread. Small columns are only built in the lower sections of the FAB level and do not interfere with equipment arrangement; however, the main columns limit the arrangement of production equipment. It is critical to quickly construct plants for productions in the high technology industry owing to rapid technological advances and fierce competition. Therefore, to reduce the construction period of cleanrooms, the floor of the FAB level and small columns are built with steel frames while the floor of the R/P level and main columns are built with reinforced concrete.

The requirements with regard to cleanliness of air and environmental conditions have become more stringent with increased precision of production facilities and measurement equipment. This has led to larger production equipment, air conditioning units, and ducts, which in turn caused the span lengths and story heights to increase. However, the vibration performance of structures generally is weakened as the span lengths and story heights of structures increases. To design and construct the larger high tech facility structures while satisfying the stringent vibration performance condition, it is necessary to develop and improve the experimental and analytic techniques for those.

\section{Similitude Law}

3.1. Overview. The similitude law is a rule for determining the desired physical measurements for an experiment based on dimensional analysis and defines the scale effects of a prototype in physical ratios. For general dynamic problems, length $(L)$, mass $(M)$, and time $(T)$ are set as the basic dimensions, and the other parameters are determined based on a combination of the basic dimensions. For example, if the similitude for a prototype and small-scale model is defined as " $S$," then the similitude relationship between the two structures is induced as shown in Table 1 . Table 1 categorizes the similitudes based on acceleration, mass, and time, which signifies that all of the parameters cannot be appropriately scaled at once. For instance, if the similitude is $S$, the basic scale for length would be $S$. If the similitude for time cannot be adjusted or time (or frequency) effect should be equal in both the scale model and prototype, the similitude for time must be 1 . Then, the similitude for acceleration, which incorporates both length and time as per $L T^{-2}$, becomes $S$. However, if the experiment is influenced by the acceleration of gravity, this rule cannot be applied as the acceleration of gravity cannot be manipulated. 
TABLE 1: Scale factor according to the parameters.

\begin{tabular}{lcccc}
\hline Parameter & Range & \multicolumn{2}{c}{ Scale factor } \\
& & Mass-based & Time-based & Acceleration-based \\
\hline Length & $L$ & $S$ & $S$ & $S$ \\
Mass & $M$ & $S^{3}$ & 1 & $S^{2}$ \\
Time & $T$ & $S$ & 1 & $S^{0.5}$ \\
Stress & $M L^{-1} T^{-2}$ & 1 & $S$ & $S^{0.5}$ \\
Velocity & $L T^{-1}$ & 1 & $S$ & 1 \\
Acceleration & $L T^{-2}$ & $1 / S$ & $S^{2}$ & $S^{2}$ \\
Force & $M L T^{-2}$ & $S^{2}$ & $S$ & $S$ \\
Stiffness & $M T^{-2}$ & $S$ & $S$ & $S^{3 / 4}$ \\
Damping & $M T^{-1}$ & $S^{2}$ & 1 & $1 / S^{0.5}$ \\
Natural frequency & $T^{-1}$ & $1 / S$ & & \\
\hline
\end{tabular}

(i) Acceleration-Based Scaling. The acceleration ratio should be defined as 1 in order to accurately represent the gravity and inertia of a structure because even though the acceleration on a mass can be controlled, the acceleration of gravity cannot be manipulated. In this case, the similitudes for mass and time are proportional to $S^{2}$ and $S^{0.5}$, respectively, and added mass and time compression are required to conduct a dynamic test.

(ii) Time-Based Scaling. Time ratio can be set to 1 when the influence of gravity can be ignored. Then the frequency effect would be conserved for the prototype and scale model, which allows the researcher to acquire quantitative information about the internal performance of a structure. In this case, mass is proportional to $S$, so added mass is required for a dynamic test.

(iii) Mass-Based Scaling. When the influence of gravity cannot be ignored, the mass can be adjusted to be proportional to $S^{3}$. In this case, this ratio is applied to the scale model for the dynamic testing. However, researchers must take note that time is proportional to $S$.

3.2. Selection of Scaling Method for Similitude of High Tech Facility Structures. Each of the three types of similitude explained above has distinct properties, so researchers should select whichever is more appropriate for their research objective. If acceleration-based scaling is chosen, the similitude for mass becomes $S^{2}$. The similitude for length is $S$ and the mass of the scale model is reduced by $S^{3}$, in which case an additional mass $\left(S^{2}-S^{3}\right)$ should be added to the model. For example, if the similitude is $S=1 / 2$ as used in this study, each member is scaled down by $1 / 2$, and the mass ratio for the small-scale becomes $(1 / 2)^{3}$. However, the mass ratio as per the similitude must be $(1 / 2)^{2}$, which means that we need to add a mass equal to $1 / 8(=1 / 4-1 / 8)$ of the prototype. This means that we need an added mass equal to the scale model. Because the high tech facility structures are generally large, $1 / 2$ scale model of it is heavy and has the long span length and high story height. Thus, the added mass makes it difficult to set up and conduct the experimental test for high tech facility structures.
If time-based scaling method is chosen because the frequency effect is considered as the most important variable, the similitude for mass becomes $\mathrm{S}$. This signifies that the size of the added mass becomes $\left(S-S^{3}\right)$, which is a larger value than that required for the acceleration-based scaling $\left(S^{2}-S^{3}\right)$.

In the present study, $S=1 / 2$ is chosen. Therefore, we must add a mass greater than the scale model itself when we choose acceleration-based or time-based scaling method. On the other hand, if we choose the mass-based scaling method, the similitude for mass becomes $S^{3}$. This would be automatically satisfied if we apply a similitude of $S$ to the member measurements, so added mass would not be required. For this reason, the present study uses the massbased scaling method.

\section{Experimental Test}

4.1. One-Half-Scale Model. We manufacture a 1/2 scale model for the unit modules of the cleanroom as shown in Figure 2. The width, depth, and height for the model are $7.20 \mathrm{~m}, 7.20 \mathrm{~m}$, and $7.25 \mathrm{~m}$, respectively. The FAB level and the small columns are arranged in an $\mathrm{H}$-shape, and the $\mathrm{R} / \mathrm{P}$ level and the main columns are constructed with concrete. The members for the steel $\mathrm{H}$-shape should be manufactured by applying the similitude as steel is a homogenous material, but the members in the scale model are very thin, which would induce deformation when welded and would undermine constructability. Therefore, we chose rolled shape as a similar alternative. The strengths and section sizes of the materials used are shown in Table 2.

For the scale model design, when reducing the member sizes according to the scale factor $(S)$, the axial loads and moments of the section designs for the two structures have to be matched with the scale factor. Moreover, when the properties of the materials used are different, the strains of the concrete and steel frame have to be considered. In this study, since the same materials are used, the strains are not considered and the amounts of reinforcements are planned by applying the scale factor $\left(S^{3}\right)$ for the moment only, while neglecting the scale regarding the axial load effect, which has the smallest impact on the dynamic behavior of the structure. 

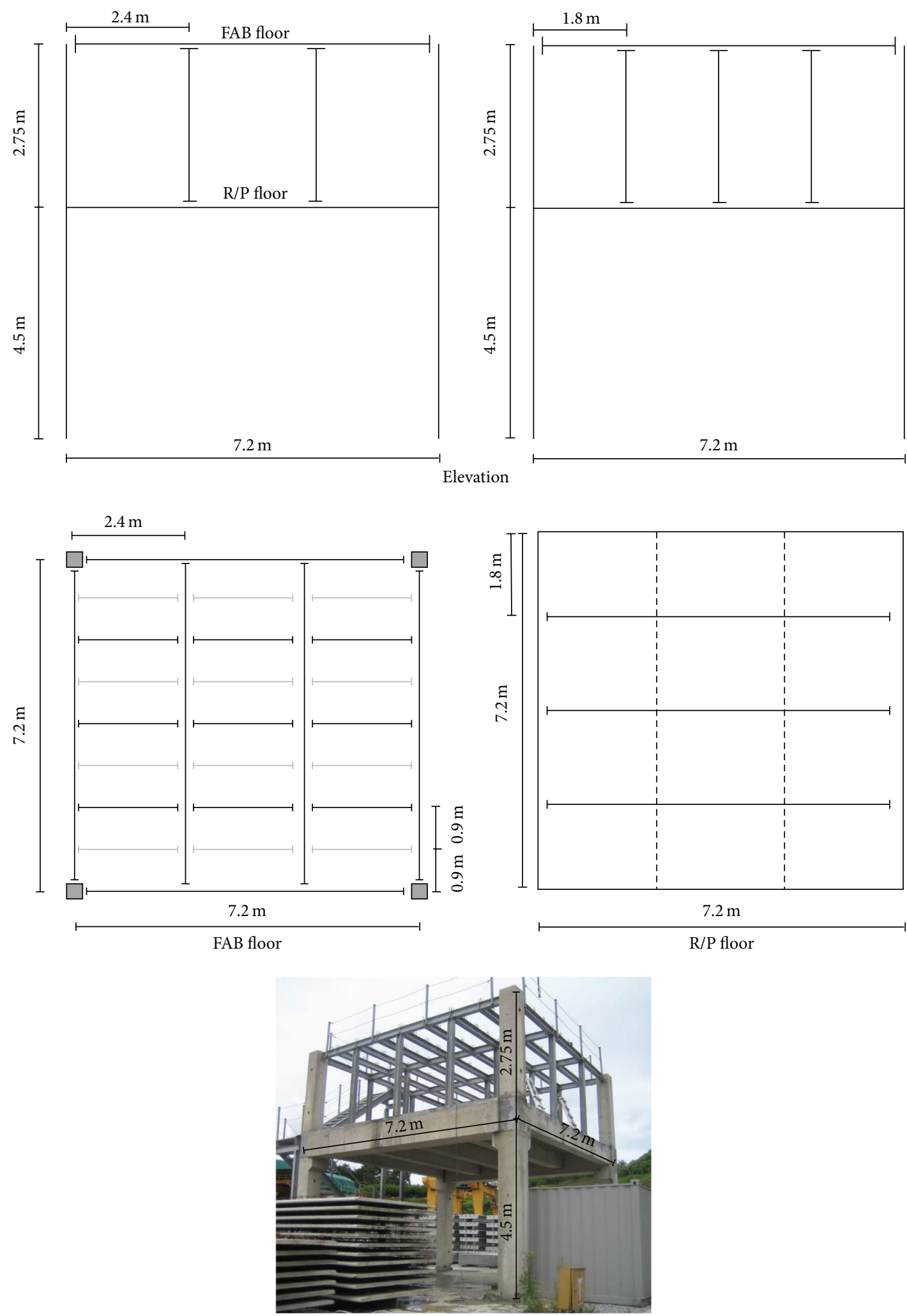

FIGURE 2: 1/2 scale model manufactured by using mass-based scaling method. 
TABLE 2: Specifications of prototype model and $1 / 2$ scale model.

\begin{tabular}{lcc}
\hline Category & Prototype model & $1 / 2$ scale model \\
\hline Member dimensions (unit: $\mathrm{mm}$ ) & & $400 \times 600$ \\
& $800 \times 1200$ & $350 \times 600$ \\
R/P floor beams & $700 \times 1200$ & $700 \times 800$ \\
& $1400 \times 1600$ & $500 \times 500$ \\
Main column & $1000 \times 1000$ & $H-220 \times 150 \times 6 \times 9$ \\
FAB floor beam & $H-440 \times 300 \times 11 \times 18$ & $H-150 \times 150 \times 7 \times 10$ \\
Small column & $H-300 \times 300 \times 15 \times 10$ & Thk. $=90$ \\
Slab & Thk. $=180$ & $7200 \mathrm{~mm} \times 7200 \mathrm{~mm}$ \\
\hline Span & $14400 \mathrm{~mm} \times 14400 \mathrm{~mm}$ & First floor: $4500 \mathrm{~mm}$ \\
\hline Story heights & First floor: $9000 \mathrm{~mm}$ & Second floor: $2750 \mathrm{~mm}$ \\
\hline Damping ratio & Second floor: $5500 \mathrm{~mm}$ & $3 \%$ \\
\hline & $3 \%$ & $27 \mathrm{MPa}$ concrete \\
Material strengths & $27 \mathrm{MPa}$ concrete & $500 \mathrm{MPa}$ rebar \\
\end{tabular}

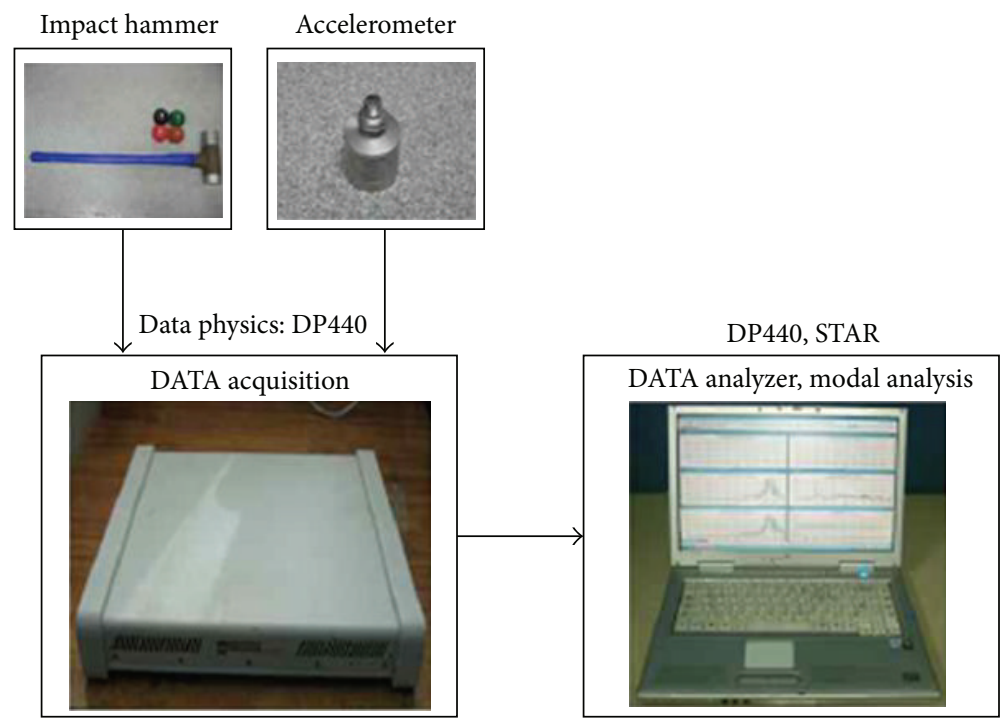

Figure 3: Equipment component used for the impact hammer test.

4.2. Impact Hammer Test. We perform an impact hammer test on the scale model to acquire data required for the validation of the analytical modeling technique. The objective of the impact hammer experiment in this study is to derive a transfer function for the prototype. To this end, impact hammer experiment is performed using the equipment shown in Figure 3. First, we strike the structure with the impact hammer to induce vibration. The exciting force $f(t)$ and response $x(t)$ from the structure are measured by the sensor on the impact hammer and accelerometer installed on the structure, respectively. The collected data is analyzed via the data analyzer. The exciting force $f(t)$ and response $x(t)$ are functions of time but can be converted into functions of frequency using the Fourier transform. The transformed response $X(\omega)$ and exciting force $F(\omega)$ are used to derive a transfer function $H(\omega)$ as shown in (1). A transfer function is a unique property of a structure that represents the size of response for a unit exciting force. Hence, it is an appropriate comparative index for the evaluation of the accuracy of modeling by the analytical modeling technique:

$$
H(\omega)=\frac{X(\omega)}{F(\omega)} .
$$

\section{Analytical Validation}

5.1. Comparison of Transfer Functions Using Data from Scale Model Experiment. We produce an analytical model for the $1 / 2$ scale model as shown in Figure 4 . In the analytical model, the sizes of the members are determined by the design values shown in Table 2. The modulus of elasticity for concrete is set to the standard value based on the concrete strength. Although the damping value should vary depending on the mode, a uniform value is used for the analysis because it 
TABLE 3: Rebar ratios of beam members.

\begin{tabular}{l}
$\begin{array}{l}\text { Type of } \\
\text { beams }\end{array}$ \\
\hline Section
\end{tabular}

TABLE 4: Comparison of the simulated and measured frequencies.

\begin{tabular}{|c|c|c|c|c|c|}
\hline \multirow[t]{2}{*}{ Mode } & \multirow[t]{2}{*}{ Frequencies by an experimental test $(\mathrm{Hz})$} & \multicolumn{2}{|c|}{$\begin{array}{l}\text { Frequencies simulated without } \\
\text { the consideration for the stiffness of } \\
\text { rebars }\end{array}$} & \multicolumn{2}{|c|}{$\begin{array}{l}\text { Frequencies simulated with } \\
\text { the consideration for the stiffness of } \\
\text { rebars }\end{array}$} \\
\hline & & $(\mathrm{Hz})$ & Error rate (\%) & $(\mathrm{Hz})$ & Error rate (\%) \\
\hline 1 st & 16.25 & 13.90 & 16.91 & 16.11 & 0.87 \\
\hline 2nd & 27.75 & 33.80 & 17.90 & 27.34 & 1.50 \\
\hline $3 \mathrm{rd}$ & 30.50 & 39.50 & 22.78 & 31.25 & 2.40 \\
\hline
\end{tabular}

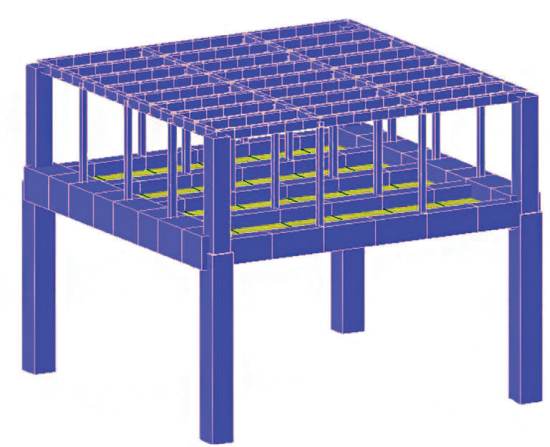

Figure 4: Perspective view of the analytical model.

requires a damping value for frequencies that cannot be empirically calculated.

The simulation indicates about $20 \%$ error for natural frequency compared to the results of the experiment. To reduce this error, we examined the potential effects of various parameters and input values and found that considering the effect of reinforcement embedded in concrete would reduce error the most. In general, safety evaluations using static analysis of reinforced concrete structures can assume that the members of a structure are constructed purely with concrete without considering the effects of embedded reinforcement because the stiffness ratio for the members is more important. However, it is shown that analysis of microvibrations should consider the effects of reinforcement because the stiffness of each member has a considerable impact on the structure's dynamic behavior.

Therefore, we considered the effects of embedded reinforcement during our modeling of the concrete members. To this end, we applied the transformed area concept, in which

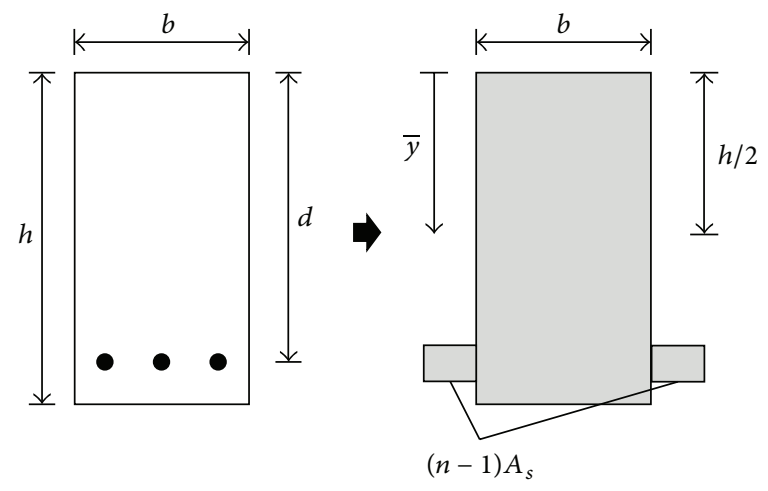

$n$ is the ratio of reinforcements to concrete

$A_{s}$ is the total cross-sectional area of reinforcements

FIGURE 5: The transformed area concept.

the cross-sectional area of the steel is transformed into that of concrete with equivalent axial stiffness as shown in Figure 5. Applying this concept to beam members with rebar ratios in Table 3 produced similar results with the experiment as shown in Figure 6. It is confirmed that two transfer functions from the experiment and numerical analysis show the good agreement.

Figure 7 and Table 4 show the mode shapes and frequencies of the experimental and analytic models. It is shown that the difference errors of the first, second, and third frequencies obtained from the simulated model with the consideration for the stiffness of rebars are reduced from $16.91 \%, 17.90 \%$, and $22.78 \%$ to $0.87 \%, 1.50 \%$, and $2.40 \%$, respectively.

The size of a mesh in finite element analysis influences the accuracy $[30,31]$. It is necessary to check whether the 


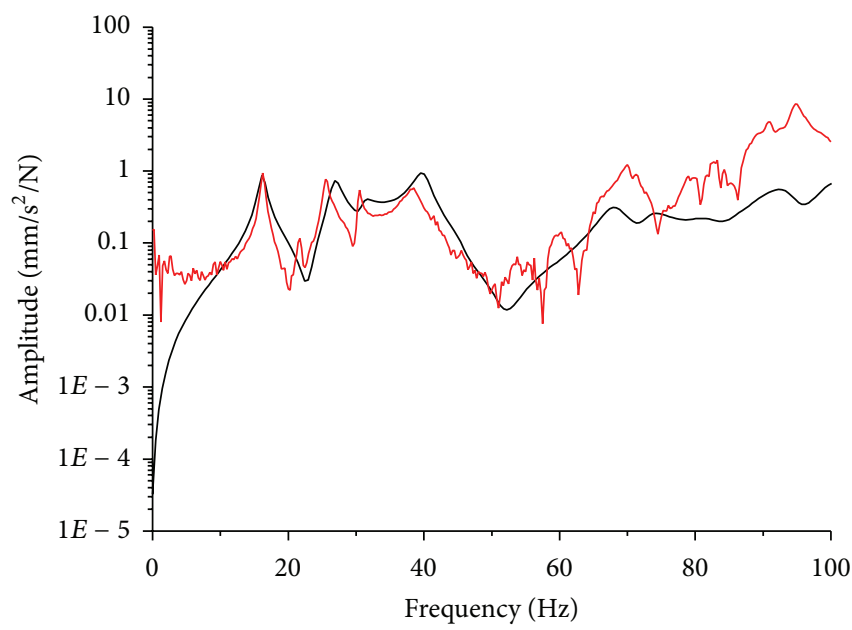

- Analytical data

_ Experimental data

(a) FAB floor

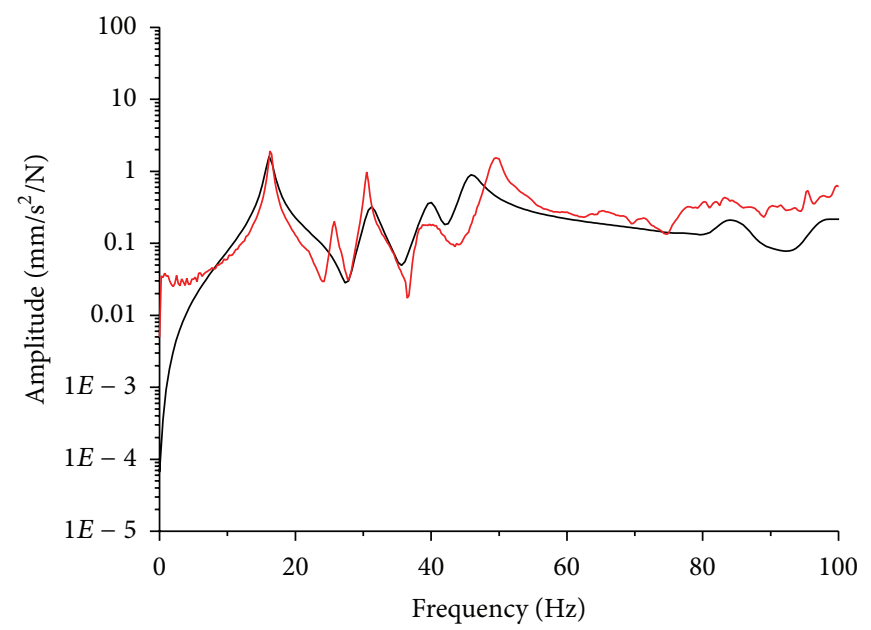

Analytical data

- Experimental data

(b) $\mathrm{R} / \mathrm{P}$ floor

FIGURE 6: Comparisons of transfer functions from the experiment and numerical analysis.
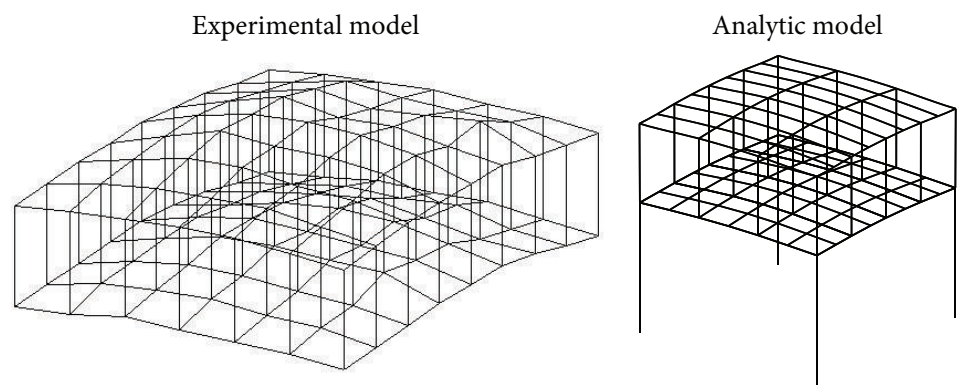

(a) 1st-mode shape
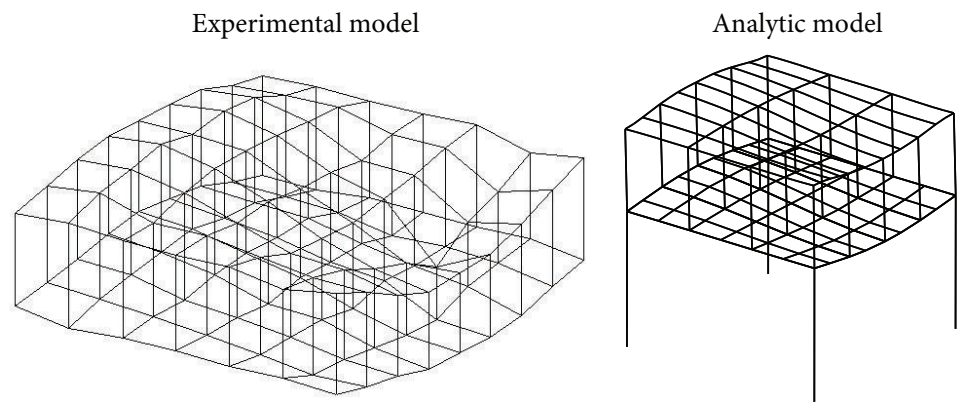

(b) 2nd-mode shape

Experimental model
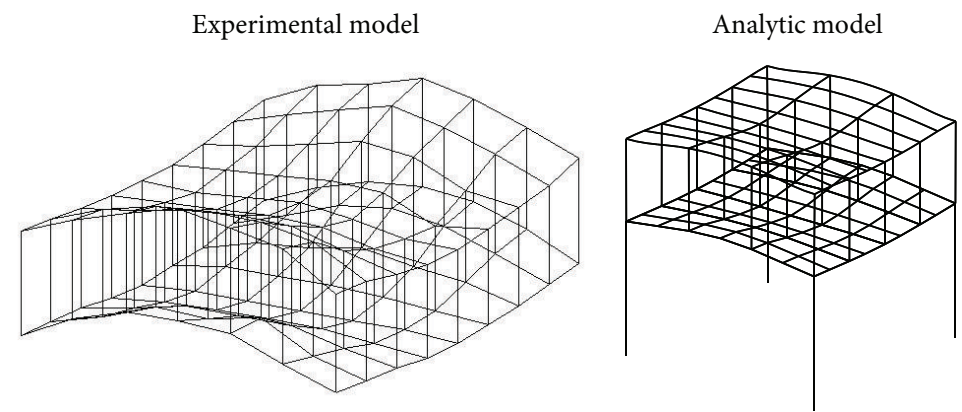

(c) 3rd-mode shape

FIGURE 7: Comparison of the mode shapes obtained from the experimental and analytic models. 
TABLE 5: Comparison of natural frequencies from the prototype model and 1/2 scale model.

\begin{tabular}{lccc}
\hline Mode & $1 / 2$ scale model & Prototype model & Ratio of response amplitude \\
\hline 1st & 13.9 & 6.9 & 2.01 \\
2nd & 33.8 & 16.9 & 2 \\
3rd & 39.5 & 19.7 & 2 \\
4th & 78.5 & 39.7 & 1.97 \\
5th & 97.4 & 48.7 & 2 \\
\hline
\end{tabular}

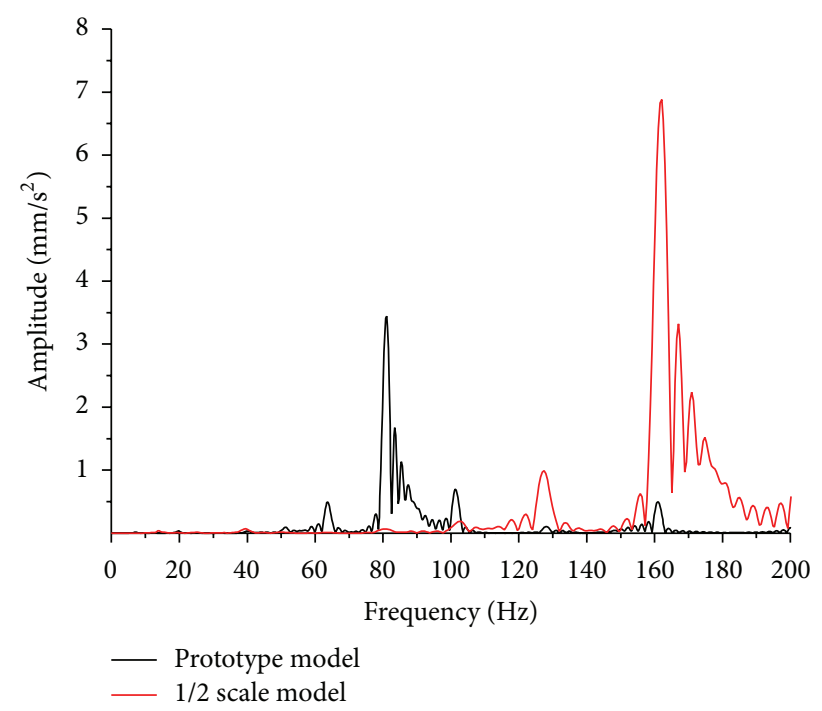

(a) FAB floor

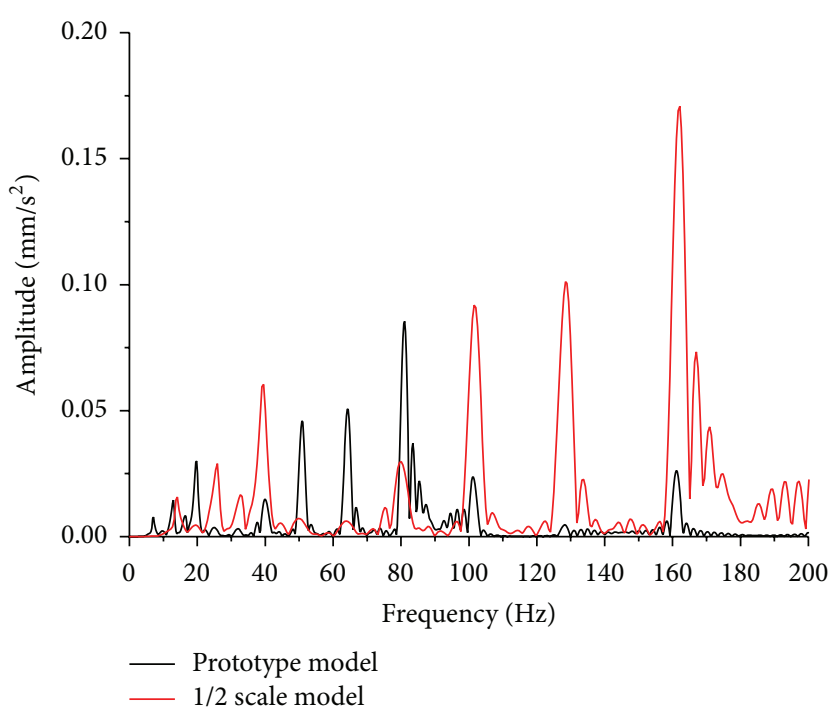

(b) R/P floor

FIGURE 8: Comparisons of response results from the prototype model and 1/2 scale model.

size of a mesh is appropriate. The fine mesh is employed to investigate the local behaviors or the higher mode effects of a structure. Otherwise, it is known that when global response is of primary interest, the coarse-mesh model is attractive [32]. Because the mass participation factor of low-rise buildings for the first mode is generally more than $90 \%$, the coarsemesh model can be considered for the vibration analysis of low-rise buildings. It was shown that the mass participation factor of the first mode for the target structure used in this study was $99.45 \%$ and the difference between the first natural frequencies from the experimental and simulated results in Table 4 was $0.87 \%$. Because the acceptable error rate was obtained, there was no necessity to modify the size of mesh employed in this study. If it is necessary to improve the accuracy of vibration analysis, the effects of the mesh size, nonstructural components, and so on can be considered [25, $26,30,31]$.

5.2. Validation of Similitude. In order to validate the similitude law used for designing and manufacturing the smallscale model, we create an analytical model for the prototype using the analytic technique suggested in Section 5.1. The analytical model for the prototype is compared with the small-scale analytical model, which is validated by comparing its results with that of the small-scale modeling experiment, in order to validate the similitude law. The analytical modeling technique that is applied to the small-scale analytical model and prototype analytical model is validated via the data from scale modeling experiment, so it is thought that verifying the similitude via a comparison of the two analytical models is valid. The design data for the prototype is shown in Table 2.

The comparison of the two analytical models is shown in Table 5 and Figure 8. As shown in Table 1, if mass-based scaling (similitude of $S$ ) is applied, the natural frequency of the small-scale model should be $1 / S$ of that of the prototype. The results showed that the frequencies of a scale model that is considered are double those of the prototype, signifying that the mass-based similitude law is indeed valid.

\section{Conclusion}

As a preliminary study for the development of technology for microvibration designs for cleanroom structures, this study performed a scale modeling experiment and analytical validation of the scaling. First, we manufactured a $1 / 2$ smallscale model for the unit modules of a cleanroom based on the mass-based similitude law and tested the model for its dynamic properties. The experimental results were compared with those of the analysis to acquire an improved analytical modeling.

During the process of fitting with the experimental results, it was found that considering the contributions from 
the stiffness of the embedded reinforcement in the concrete would generate more accurate analytical results. In other words, microvibration response, which is considered highly important in evaluating performance for high technology facilities, is sensitive to the stiffness of each member of the structure. Therefore, it is necessary that evaluations of microvibration in high technology facilities take into account the impact of reinforcement. Such analytical modeling technique can contribute to improving the technology for microvibration designs by validating various ideas and examining the effects of design parameters.

Meanwhile, we compared the results produced by the prototype analytical model and small-scale analytical model for cleanroom unit modules to validate the mass-based similitude law used in this study. The results were found to be in line with theory. We expect these outcomes to be used for reference in planning scale model experiments for high technology facilities as well as other large structures in the future.

\section{Competing Interests}

The authors declare that there is no conflict of interests regarding the publication of this paper.

\section{Acknowledgments}

This research was supported by Basic Science Research Program through the National Research Foundation of Korea (NRF) funded by the Ministry of Education (NRF2014R1A1A2059874).

\section{References}

[1] K. A. Salyards and R. J. Firman III, "Review of generic and manufacturer design criteria for vibration-sensitive equipment," in Proceedings of the IMAC-XXVII: Conference \& Exposition on Structural Dynamics, 2009.

[2] E. E. Ungar, D. H. Sturz, and C. H. Amick, "Vibration control design of high technology facilities," Sound and Vibration, vol. 24, no. 7, pp. 20-27, 1990.

[3] H. Amick, "On generic vibration criteria for advanced technology facilities: with a tutorial on vibration data representation," Journal of the Institute of Environmental Sciences, vol. 40, no. 5, pp. 35-44, 1997.

[4] C. G. Gordon, "Generic criteria for vibration-sensitive equipment," in Vibration Control in Microelectronics, Optics, and Metrology, vol. 1619 of Proceedings of SPIE, pp. 71-85, San Jose, Calif, USA, 1992.

[5] C. J. Montgomery, H. Amick, P. Haswell, J. Dibattista, and M. S. Medhekar, "Use of vibration criteria in the selection of structural systems for nanotechnology research facilities," in Buildings for Nanoscale Research and Beyond, vol. 5933 of Proceedings of SPIE, pp. 1-12, San Diego, Calif, USA, July 2005.

[6] H. Amick, M. Gendreau, T. Busch, and C. G. Gordon, "Evolving criteria for research facilities: vibration," in Buildings for Nanoscale Research and Beyond, vol. 5933 of Proceedings of SPIE, San Diego, Calif, USA, 2005.

[7] C.-L. Lee, Y.-P. Wang, and R. K. L. Su, "Assessment of vibrations induced in factories by automated guided vehicles," Proceedings of the Institution of Civil Engineers: Structures and Buildings, vol. 166, no. 4, pp. 182-196, 2013.

[8] T.-C. Pan, X. You, and C. L. Lim, "Evaluation of floor vibration in a biotechnology laboratory caused by human walking," Journal of Performance of Constructed Facilities, vol. 22, no. 3, pp. 122-130, 2008.

[9] J. M. W. Brownjohn, T.-C. Pan, C. Middleton, S. C. Tan, and G. Yang, "Floor vibration serviceability in a multistory factory building," Journal of Performance of Constructed Facilities, vol. 30, no. 1, Article ID 04014203, 2016.

[10] M. Ismail, J. Rodellar, and F. Ikhouane, "An innovative isolation bearing for motion-sensitive equipment," Journal of Sound and Vibration, vol. 326, no. 3-5, pp. 503-521, 2009.

[11] M. Ismail, J. Rodellar, and J. R. Casas, "Seismic behavior of RNC-isolated bridges: a comparative study under nearfault, long-period, and pulse-like ground motions," Advances in Materials Science and Engineering, vol. 2016, Article ID 1897045, 18 pages, 2016.

[12] B.-W. Huang, J.-H. Kuang, J.-G. Tseng, J.-C. Wang, and Y.X. Qiu, "Seismic analysis of a viscoelastic damping isolator," Advances in Materials Science and Engineering, vol. 2015, Article ID 280625, 6 pages, 2015.

[13] W. Taniwangsa, "Seismic performance of a base-isolated demonstration building," Earthquake Spectra, vol. 18, no. 4, pp. 777793, 2002.

[14] H. Amick, S. Hardash, P. Gillett, and R. J. Reaveley, "Design of stiff, low-vibration floor structures," in Vibration Control in Microelectronics, Optics, and Metrology, vol. 1619 of Proceedings of SPIE, pp. 180-191, San Jose, Calif, USA, 1992.

[15] A. Pavic and P. Reynolds, "Vibration serviceability of longspan concrete building floors. Part 1: review of background information," Shock and Vibration Digest, vol. 34, no. 3, pp. 191211, 2002.

[16] C. J. Middleton and J. M. W. Brownjohn, "Response of high frequency floors: a literature review," Engineering Structures, vol. 32, no. 2, pp. 337-352, 2010.

[17] C. Q. Howard and C. H. Hansen, "Vibration analysis of waffle floors," Computers and Structures, vol. 81, no. 1, pp. 15-26, 2003.

[18] J. M. Bracci, A. M. Reinhorn, and J. B. Mander, "Seismic resistance of reinforced concrete frame structures designed for gravity loads: performance of structural system," ACI Materials Journal, vol. 92, no. 5, pp. 597-609, 1995.

[19] L. A. Fahnestock, J. M. Ricles, and R. Sause, "Experimental evaluation of a large-scale buckling-restrained braced frame," Journal of Structural Engineering, vol. 133, no. 9, pp. 1205-1214, 2007.

[20] L. Zeng, Z. Cui, Y. Xiao, S. Jin, and Y. Wu, "Cyclical behavior of concrete-encased composite frame joints with high strength concrete," Advances in Materials Science and Engineering, vol. 2015, Article ID 873162, 13 pages, 2015.

[21] Y. Zhou, T. Kijewski, and A. Kareem, "Along-wind load effects on tall buildings: comparative study of major international codes and standards," Journal of Structural Engineering, vol. 128, no. 6, pp. 788-796, 2002.

[22] J.-S. Hwang, A. Kareem, and H. Kim, "Wind load identification using wind tunnel test data by inverse analysis," Journal of Wind Engineering and Industrial Aerodynamics, vol. 99, no. 1, pp. 1826, 2011.

[23] S. W. Choi, J. H. Seo, H. M. Lee, Y. Kim, and H. S. Park, "Wind-induced response control model for high-rise buildings based on resizing method," Journal of Civil Engineering and Management, vol. 21, no. 2, pp. 239-247, 2015. 
[24] A. M. Raich and T. R. Liszkai, "Multi-objective optimization of sensor and excitation layouts for frequency response functionbased structural damage identification," Computer-Aided Civil and Infrastructure Engineering, vol. 27, no. 2, pp. 95-117, 2012.

[25] R. K. L. Su, A. M. Chandler, M. N. Sheikh, and N. T. K. Lam, "Influence of non-structural components on lateral stiffness of tall buildings," The Structural Design of Tall and Special Buildings, vol. 14, no. 2, pp. 143-164, 2005.

[26] J. Y. Kim, E. Yu, D. Y. Kim, and S.-D. Kim, "Calibration of analytical models to assess wind-induced acceleration responses of tall buildings in serviceability level," Engineering Structures, vol. 31, no. 9, pp. 2086-2096, 2009.

[27] T. Xu, "Characterization of minienvironments in a clean room: design characteristics and environmental performance," Building and Environment, vol. 42, no. 8, pp. 2993-3000, 2007.

[28] Y.-C. Shih, A.-S. Yang, and C.-W. Lu, "Using air curtain to control pollutant spreading for emergency management in a cleanroom," Building and Environment, vol. 46, no. 5, pp. 11041114, 2011.

[29] K.-C. Noh, H.-S. Kim, and M.-D. Oh, "Study on contamination control in a minienvironment inside clean room for yield enhancement based on particle concentration measurement and airflow CFD simulation," Building and Environment, vol. 45, no. 4, pp. 825-831, 2010.

[30] C. H. Lee, K. B. Song, and H. W. Kim, "Vibration analysis and evaluation for the offshore structure using simplified model and RSS method," in Proceedings of the ASME 31st International Conference on Ocean, Offshore and Arctic Engineering (OMAE '12), pp. 637-641, American Society of Mechanical Engineers, Rio de Janeiro, Brazil, July 2012.

[31] M. Imregun, K. Y. Sanliturk, and D. J. Ewins, "Finite element model updating using frequency response function data: II. Case study on a medium-size finite element model," Mechanical Systems and Signal Processing, vol. 9, no. 2, pp. 203-213, 1995.

[32] D. J. Nefske and S. H. Sung, "Correlation of a coarse-mesh finite element model using structural system identification and a frequency response assurance criterion," in Proceedings of the SPIE the International Society for Optical Engineering, SPIE International Society for Optical, 1996. 

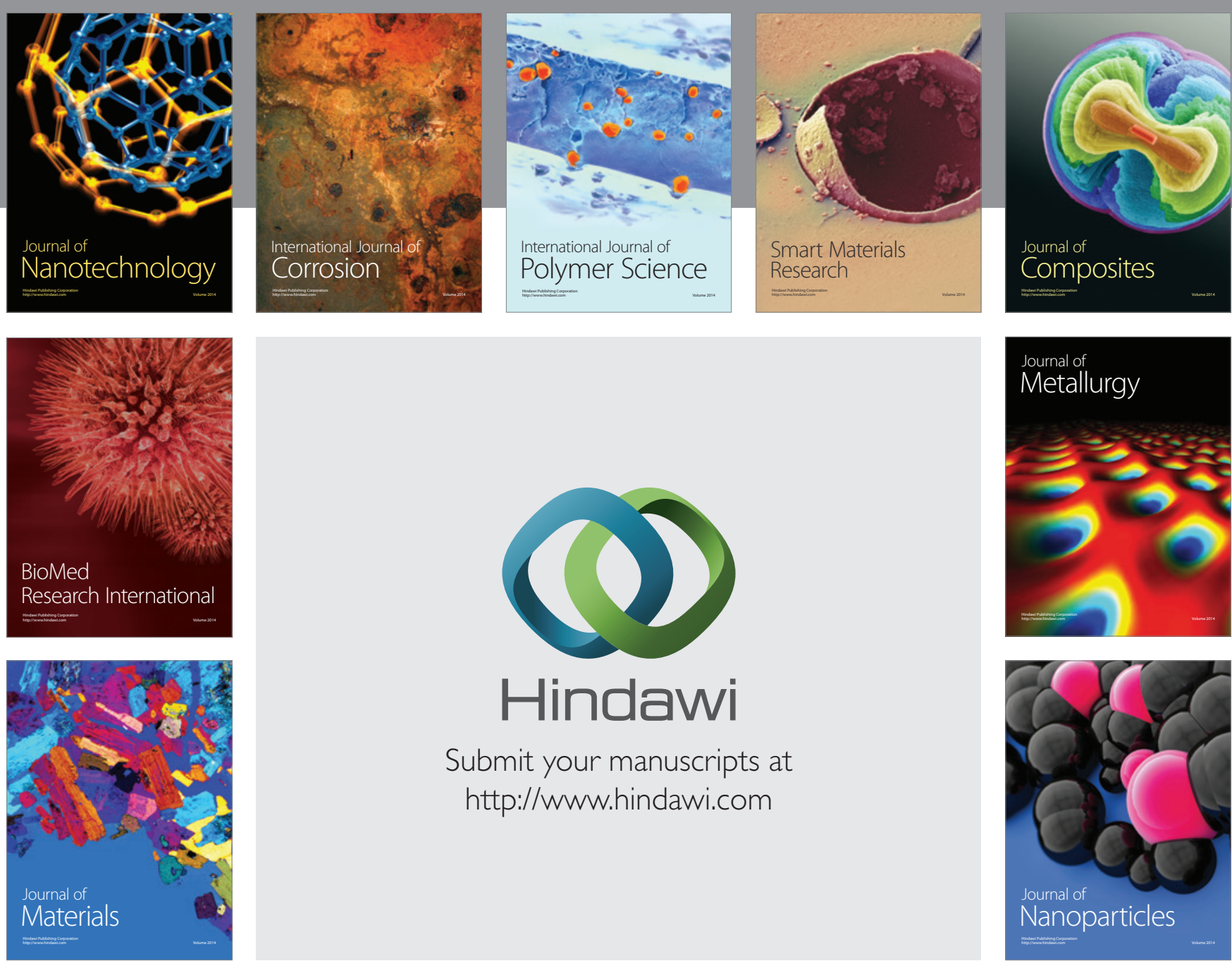

\section{Hindawi}

Submit your manuscripts at

http://www.hindawi.com

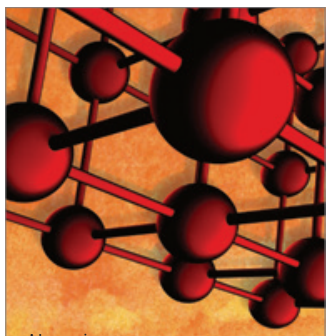

Materials Science and Engineering
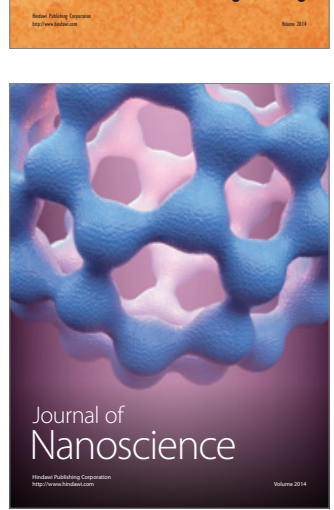
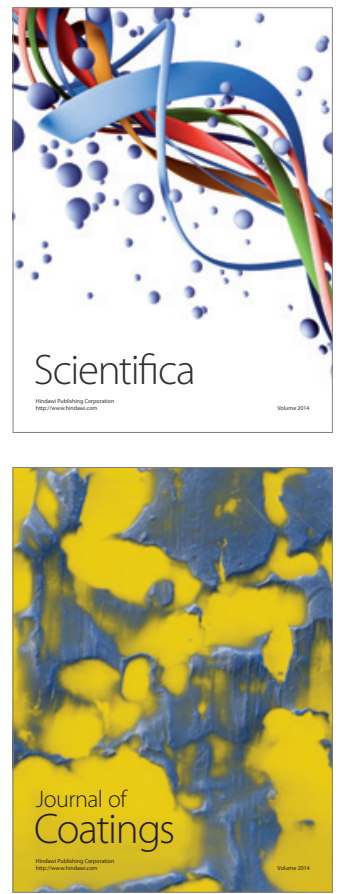
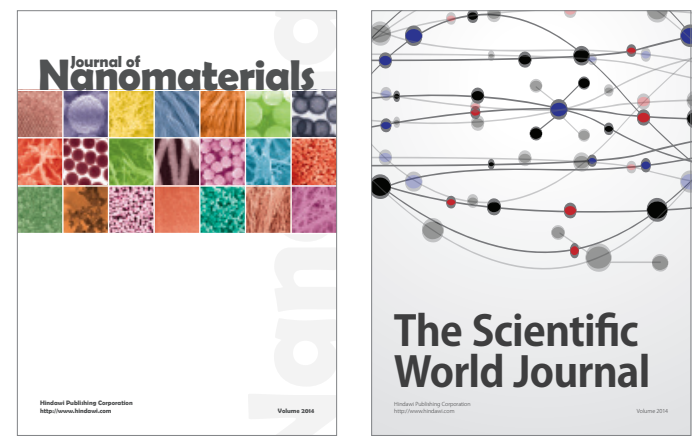

The Scientific World Journal
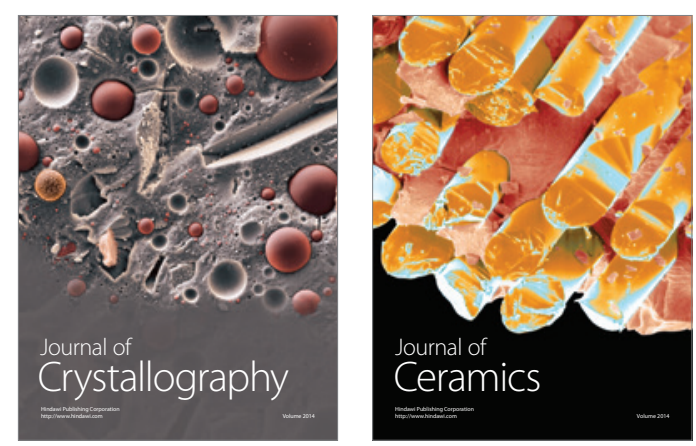
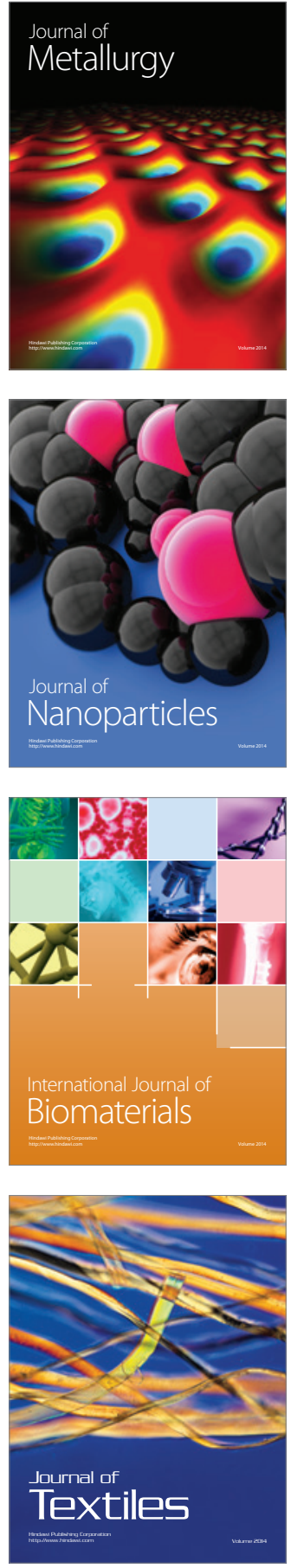